\title{
New Media Marketing Strategy Based on Word-of-Mouth of Wanghong
}

\author{
Quanhong Liu, Yuxuan Zhang \\ School of Business, Jianghan University \\ Wuhan, P. R. China
}

\begin{abstract}
New media marketing, the marketing model in the context of new era for companies, is right at the rapid development. How to utilize the power of Wanghong and new media effectively to serve corporate marketing much better is worth exploring. Based on new media marketing, this paper discusses the influence of word-of-mouth of Wanghong on new media marketing strategy and puts forward the policy suggestion on practice of marketing in the way Wanghong affects consumer behavior.
\end{abstract}

Keyword —new media marketing; opinion leader; Wanghong; word-of-mouth

\section{INTRODUCTION}

With the development of internet technology, media continues deriving and evolving with the advancement of digital information and technology, which turns out to be a catalyst for the emergence of more and more new media. In addition, there has been changes in the channels where people obtain information and the representatives of traditional media are phasing out along with the channels. While characterized by instant messaging, the new media starts to rise to prominence, attracting more and more attentions from the public. New media marketing is exactly the mode of utilizing the new media platforms for marketing activities. New media, which features wide audience, high efficiency and great interaction, is increasingly becoming an important platform for marketing. New media marketing, the marketing mode of guiding consumers psychologically based on the conceptual appeal and problem analysis of the specific products, is more concerned about depth of products and interactivity with consumers.

The advancement of big data and mobile internet provides users with diversified channels to obtain information and reduces the users' reliance on traditional media, and consumers are converted to obtain information actively rather than sit there receiving it passively. In the meantime, user requirements are progressively refined. It is certain that new media will be increasingly important and become the main channel in network marketing for companies with the young generation growing up. Then, companies will revolutionize proactively and take advantage of new media marketing with the time development tidal current.

In order to enhance brand recognition, goodwill and customer loyalty, companies should not only depend on internal forces (marketing department), but also make use of the external forces (consumer's word-of-mouth) for marketing, to disseminate information about corporates and brands, and the development of the internet provides a new carrier with word-of-mouth, that is internet word-of-mouth.

As the new media continues to emerge, companies utilize new media platforms for promoting brands and products. Wanghong, internet celebrity, is able to offer great help for company to operate new media marketing. In nature, Wanghong is an opinion leader, the importance and influence of whom is self-evident. And accompanied by new media marketing, Wanghong originates in network. How to utilize the power of word-of-mouth of Wanghong effectively for new media marketing is worth exploring.

\section{THE RISE OF NEW MEDIA MARKETING}

With the advancement of internet technology, the network era has stepped from Web1.0 to Web 3.0. With the popularity of internet and the advancement of e-commerce, the marketing areas and patterns of companies will face new opportunities and challenges, with various forms of marketing strategies sprouting. New media is a new form of media comparing to traditional media and comes after it. New media includes network media, mobile media, digital media and the like (Wang, 2009) [1].

\section{A. As internet and communication technology progress, new media is increasingly presenting the powerful advantages that are mainly as follow:}

1) Wide audience. The 39th Statistical Report on internet Development in China, published by China internet Network Information Center (CNNIC), shows up to December 2016, the number of net citizens in China has reached 731 million. The number of mobile net citizens in China has reached 695 million with an increase of more than $10 \%$ for three consecutive years. The number of the audience of new media marketing has shown an increasing trend.

2) High efficiency. New media marketing depends merely on new media platforms to operate without time and distance limits. Compared with traditional marketing, the marketing costs have been reduced significantly

3) Great interaction. Different from traditional marketing which focuses more on the coverage of products, new media marketing is concerned more about its advantages of new media marketing platforms to strengthen interactions within consumers to build profitable customer relationships so as to 
meet the goals of advertising of corporate brands and selling of products.

\section{B. Correspondingly, the strengths of new media marketing are mainly as follow:}

1) Makes it possible for independent consumer choices and effective interactions. In the era of new media, companies which undertake network marketing should engage people and spread products and messages to win trust from consumers. The advancement of internet provides people with tons of information, but also makes it harder for business decisions. In order to achieve scientific decision making and precision marketing, companies must obtain mass information and engage consumers in network marketing, which lowers the costs of acquiring information as well. Companies are able to obtain much more data to regulate the directions of the research and develop products through interactive communications with consumers. In the new media age, users place the center of market and the demands of consumers determine the market orientations.

2) Reduces marketing costs effectively. In the era of new media, more marketing channels have been presented to companies. With the emergence of new media, companies can utilize some free platforms for marketing, which expands the channels in network marketing and reduces disseminating costs. With the advancement of internet, convenient access has been provided for corporate network marketing. As long as the published content is rich in newness and creativity, it will resonate with consumers and they will take the initiative to spread. The development the new media has quickened the pace of information disseminations, and companies can achieve low-cost inputs and great-influence spreads.

3) Provides sites for creation of advertisements. The advancement of internet technology proves to be a catalyst for the emergence of diversified marketing forms, for instance, viral marketing, database marketing, community marketing, interactive experience, focus penetration, word-of-mouth, reverse communication, precision marketing, event marketing and so forth. In the era of new media, consumers are more concerned about the content with advertisements, and creative and fancy advertisements are more likely to please the eye of the consumers, which prompts them to spread actively. Creativity can be greatly powerful for advertisements, attracting more and more consumers. As the internet progresses, a large number of new technologies have been popping up, offering the flow of inspirations for corporate planning. Companies can obtain wide-ranging information, offer constant new elements for network marketing so as to appeal to the attention of consumers.

4) Encourages customers to participate in product creation. With the rise of new media, users have more and more access to obtain information and participate in product designs conveniently. To engage users in product designs can inspire creativity and vitality of them and tap into their potentials, and companies will reward those with contributions, attracting more and more users and form customer engagement and customer loyalty. Then, companies expand the business marketing field and build brand image through the loyal users. On account of the users' participation in product designs, they hope the creative idea they put forward can be widely known and spare no effort to help advertise the product information for the companies to involve more users. The user behaviors directly bring more fans, which promotes the development of companies. The emergence of new media provides users with convenient access to participate in product designs and personifies the products. When the products with emotional characteristics are spreading, they will be much easier to resonate with users and they will turn into the loyal customers of the companies.

5) Satisfies personalized needs more precisely. Compared with traditional media, the greatest hallmark of new media marketing is to provide consumers with personalized and customized services. Ad button is set in portal sites and search engines are indexing adwords. All media are focusing on customer positioning and meeting long tail needs of customers. With the advancement of mobile internet, the products which are strikingly personal are more preferable to customers and market itself offers convenience for consumer demands, enabling to position users precisely. Companies can achieve scientific decision making and precision marketing after obtaining users' information accurately.

6) Expands channels for companies to obtain user's information. In everyday life, users interact with each other through social platforms whose information will be obtained by companies through diverse means. Nowadays, the development of big data and mobile internet technology provides the technical support for companies to obtain users' information and predict the trends of consumption through analysis, then attracting potential customers. Users usually register the social platforms with detailed personal information, such as name, age, occupation, hobby, address and so forth to appeal to those from the same regions or for related cause. And users will share something relating to them on social platforms. Unconscious behaviors of users will become the competitive resources within companies.

\section{INTERNET WORD-OF-MOUTH AND NEW MEDIA}

Focus on customers, marketing is the fundamental activity in companies. When launching marketing campaigns, companies utilize advertising bombardment and customers are immersed in the world of advertisements. However, when it reaches a certain level, emotional resistance and boredom will generate, and even customers will get the feeling of being threatened. For companies, those marketing modes have lost all meaning.

For disseminating corporate valve, improving the brand's popularity and promoting the market influence, companies should not only spread information about corporates and products but also make use of the influence of consumers subtly. With the birth of new media, companies must attach 
importance to how to utilize, drive and manage its internet word-of-mouth.

Dichter (1966) [2] studied the mechanism of word-of-mouth at the first beginning and claimed that: when consumers hold the belief that advertising is a tool marketing more than information and guidance, they would get the feeling of being threatened and turn to the spread by word-of-mouth to solve the problem on purchase. Wetzer, Zeelenberg and Pieters (2007) [3] argued that word-of-mouth was the phenomenon for consumers to talk with other consumers frequently about their purchasing experience (Henning-Thurau, et al., 2004) [4]. The internet word-of-mouth based on network platforms helps consumers' purchase decision-making and avoid negative consuming experience ( Prendergast, Ko and Yuen, 2010) [5].

Traditional word-of-mouth is mainly through face-to-face communication. With the development of the internet, the spread channel in word-of-mouth also expands to the network. Tens of thousands or even millions of users receive and use emails or other network media potentially to disseminate information, leading to the faster spread speed for internet word-of-mouth, compared to the traditional word-of-mouth.

Word-of-mouth is actually telling stories. The real consumers share the real purchasing stories and experience of using products, which affects the surrounding consumer emotions naturally. Moreover, emotions play an important role in consumer buyer behaviors, so to utilize word-of-mouth marketing is a wise choice for companies.

With the renewal and development of internet technology, media continues deriving and evolving, and the carrier of word-of-mouth is increasingly diversified. Traditional word-of-mouth influence is mainly through face-to-face communication. While nowadays, the channels for spreading progressively expand for word-of-mouth based on new media platforms. Based on social network media, internet word-of-mouth comes into being, whose coverage and spreading speed is beyond comparison, and the influence of which is self-evident. The birth of internet word-of-mouth and new media marketing both benefit from the innovation of mobile internet technology. Companies utilize the power of internet word-of-mouth for new media marketing to achieve complementarity and coherent entity.

\section{WANGHONG'S EFFECT ON WORD-OF-MOUTH}

Companies are the economic organizations for profit orientation, and resources are indispensable if companies want to achieve profits. With the continuous updates and development of internet technology, New Economy, based on internet, is Attention Economy. Goldhaber (1997) [6] first put forward the idea of Attention Economy. He argued in the times of internet, information is not scarce resource at all, but surplus instead. The only scarce resource is people's attention compared with excess information. The nature of the rising New Economy, based on internet, is Attention Economy where the most significant resource is neither traditional currency capital nor information itself, but attention. The campaigns will be launched on scrambling for attentions throughout the world and the one who appeals to more attentions will dominate the world. A person's attentions will be usually influenced by surroundings, especially for reference groups often influence the others, and people's behaviors. Marketers try to identify the reference groups of their target markets. Reference groups expose a person to new behaviors and lifestyles, influence the person's attitudes and self-concept, and create pressures to conform that may affect the person's product and brand choices. The importance of group influence varies across products and brands (Guo, 2004) [7]. It tends to be stronger when the product is visible to whom the buyer respects, and opinion leader is the special type of the reference group.

As the new media continues to emerge, the needs to utilize new media platforms for companies are growing increasingly and Wanghong is the natural outcome in the context of the development of new media. Wanghong owns the strong speech power on the platforms because of remarkable characteristics with considerable attractions and exerts great influence on the others on the platforms through knowledge, special skills, personality, or other characteristics, and the importance and influence of whom is self-evident. Moreover, it will definitely influence the purchasing behaviors of the fans. Wanghong plays an indispensable role as a bridge for companies to utilize word-of-mouth of Wanghong for new media marketing on social platforms, such as, advertising brands, promoting products and so forth. In addition, this way is an organic combination that is composed of marketing subject, marketing carrier and marketing tool. The carrier for new media marketing does not originate in Wanghong, but Wanghong is born to be the carrier for new media marketing.

\section{V.New Media Marketing Strategies BASED ON WORD-OF-MOUTH OF WANGHONG}

\section{A. Discovering Wanghong}

In nature, Wanghong is an opinion leader, and its image should represent the image of corporate brand. Brands are one of the most enduring asset of a company and represent consumers' perceptions and feelings about a product and its performance. Firstly, companies should tap into the personified factors in corporate brands and then get the brands personified.

Companies are profit-oriented and marketing tools are indispensable. As mentioned above, Wanghong is born to be the carrier for new media marketing, so Wanghong has the opportunity to be the celebrity for corporate brands. However, corporate brand, with its own relative independence, is rich in the legendary stories of innovation and entrepreneurship and chasing dreams bravely by earlier generations. Wanghong, in nature, is the individual based on a person. Moreover, appearance, education and self-cultivation should be the primary factors for companies to take into consideration.

1) Appearance. The No.1 Wanghong in 2016 is renowned for beauty. Sister Feng, who claimed herself to be the No.1 Wanghong in China is famous for ugly. So, during the process of seeking Wanghong, appearance and internal consistency of companies should be taken into consideration.

2) Education. Education level of Wanghong is different from each other and it will have an impact on individual 
behaviors. So, during the process of seeking Wanghong, education level should be taken into account for deciding the use for companies or not.

3) Self-cultivation. Individual renders difference in self-cultivation. The virtue of Wanghong will influence the languages and behaviors. So, during the process of seeking Wanghong, self-cultivation should be an important factor taken into consideration.

\section{B. Cultivating Wanghong}

Wanghong, in nature, is the individual based on a person. Moreover, ability and self-cultivation vary from person to person. Sister Feng, the representative of countryside, appeals to great attentions from people. And a great many internet celebrities, just like Sister Feng, with no lack of the ability to build themselves and attract people's attentions, are exactly lack of education and self-cultivation. A cultured person shows his self-cultivation, and education is an important way of improving culture. After seeking for the celebrity for corporate brands, companies should start the cultivation. Culture has a civilizing influence on people, so does it on the individuals in internal and external of companies, and corporate brand is an important component of corporate culture. Hence, Wanghong, the representative of corporate brands, should be the carrier of the combination of education and self-cultivation. Companies should organize in-house training or sponsor the overseas studying for exposing Wanghong to higher education as much as possible and Wanghong improves the cultural quality and self-cultivation constantly through education.

\section{Supporting Wanghong}

Wanghong stands for corporate brand and deserves companies' wholehearted support for bringing profits. Firstly, companies should be in support of the contents, for instance, advertising words, photographs, videos and so forth. Companies are the economic organizations for profit orientation and marketing creates value. Wanghong, as the marketing carrier for companies, is aimed at achieving revenue and that is the reason why Wanghong is discovered and cultivated. Wanghong owns the strong speech power on the platforms. They exert great influence on the others on the platforms through advertising corporate brands, products, services and so forth, the audience will observe and participate in the relevant information of companies, and they will be likely to be the potential consumers. Secondly, companies should build some communicative platforms for supporting Wanghong, such as consumer communities. Marketing is building profitable customer relationships. Relying on word-of-mouth of Wanghong and trusting the recommendations, a certain number of customers become loyal. In order to maintain customer relationships, supporting Wanghong is necessary. Wanghong continues communicating with consumers to share purchasing stories and experience of using products, which affects consumer continuous purchase.

\section{Promoting Wanghong}

Wanghong serves companies and companies rely on Wanghong. Companies and Wanghong has become the organic whole because of corporate brands. When brand's popularity is improved and market influence expands, companies should further promote Wanghong at an appropriate time with an increase in customers. Many methods can promote Wanghong, for example, naming products after Wanghong, printing images of Wanghong on products, live broadcasting and interacting with Wanghong and so on. On the one hand, it is beneficial for Wanghong to advertise corporate products through personal feelings and experience. On the other hand, the influence of Wanghong expands, because there are quite a few customers who are not familiar with the new Wanghong representatives for companies. In the ways discussed above, the expansion of Wanghong's popularity follows as well. When the customers learn that the Wanghong whom they trust further expands influence, they will show a lot more trust in Wanghong and the representing products and services. When companies promote Wanghong to known by public, the influence of Wanghong will expand and the scale of the audience will enlarge, bringing constant new comers and loyal customers.

\section{E. Rewarding Wanghong}

Company will be repaid when Wanghong is rewarded. Firstly, companies should reward Wanghong with material incentive to support Wanghong, such as money from customer commission and year-end bonus and so forth. Secondly, companies ought to reward Wanghong with spiritual incentive, such as the media advertising and reports from journals of internal and external of companies. Furthermore, born with network, Wanghong's important place on the platforms should maintained by companies through exploring new platforms such as online communities and consumer communities and so forth. In the 21 st century, especially for service companies, internal marketing has been attached great importance. Internal marketing means that the service firm must orient and motivate its customer-contact employees and supporting service people to work as a team to provide customer satisfaction. Wanghong, as the special employee, also needs incentives and rewards.

\section{CONCLUSION}

With the popularity of internet and the advancement of E-commerce, the marketing areas and patterns of companies will face new opportunities and challenges, with various forms of marketing strategies sprouting. New media marketing, the new thing in the context of internet, provides new platforms and limitless business opportunities.

New media owns great influence, and it will definitely influence the purchasing behaviors of the fans. How to utilize the power of word-of mouth of Wanghong for supporting new media marketing is worth further exploring.

\section{ACKNOWLEDGMENT}

This paper is supported by the construction fund: Preponderant and Distinctive Discipline Group of Hubei Provincial Universities-Integrated Management of Economy and Industry of City Circle.

\section{REFERENCES}

[1] Y. Wang, "Research on new media marketing strategy based on the information age", Unpublished Dissertation of Shandong University, 2009.(In Chinese) 
[2] E. Dichter, "How word of mouth advertising works", Harvard Business Review, 1966, 44(6): 147-161.

[3] I. M. Wetzer, M. Zeelenberg and R. Pieters, "Never eat in that restaurant, I did: exploring why people engage in negative word of mouth communication", Psychology \& Marketing, 2007, 24(8): 661-680.

[4] T. Henning-Thurau, K. P. Gwinner, G. Walsh and D. D. Gremler, "Electronic word of mouth via consumer-opinion platforms: what motivates consumers to articulate themselves on the internet", Journal of Interactive Marketing, 2004, 18(1): 38-52.

[5] G. Prendergast, D. Ko and S. Y. V. Yuen, "Online word of mouth and consumer purchase intentions", International Journal of Advertising, 2010, 29(5): 687-708.

[6] M. H. Goldhaber, "The attention economy and the net", First Monday, 1997, 2(4).

[7] H. Guo, "Media hype under the attention economy era", Press Circles, 2004 (3): 38-39. (In Chinese) 